\title{
Errata: Analysis of sperm motility using optical tweezers
}

\section{Jaclyn M. Nascimento}

University of California, San Diego

Department of Electrical and Computer Engineering

La Jolla, California 92093-0407

E-mail: elliott@ucsd.edu

\section{Elliot L. Botvinick}

University of California, Irvine

Beckman Laser Institute and Medical Clinic

Irvine, California 92612

\section{Linda Z. Shi}

University of California, San Diego

Department of Bioengineering

La Jolla, California 92093-0435

\section{Barbara Durrant}

Zoological Society of San Diego

Beckman Center for Conservation and Research for Endangered Species

Escondido, California 92027-7000

\section{Michael W. Berns}

University of California, Irvine

Beckman Laser Institute and Medical Clinic

Irvine, California 92612

and

University of California

Department of Bioengineering

La Jolla, California 92093-0435

[DOI: $10.1117 / 1.2371122]$

This article was originally published online on 25 August 2006 with the following errors:

- Author Jaclyn M. Nascimento was listed as Jaclyn L. Nascimento;

- The caption for Table 1 contained typographical errors.

The corrected table follows.

All online versions of the article were corrected on 13 October 2006.
Table 1 Effect of laser trap duration and laser power on sperm motility.

\begin{tabular}{ll} 
& Average velocity ratio \\
\hline $5 \mathrm{sec}$ & $0.9473,+/-0.18$ \\
$10 \mathrm{sec}$ & $0.9097,+/-0.19$ \\
$15 \mathrm{sec}$ & $0.8602,+/-0.23$ \\
$420 \mathrm{~mW}$ & $0.9473,+/-0.18$ \\
$350 \mathrm{~mW}$ & $0.9251,+/-0.14$ \\
$300 \mathrm{~mW}$ & $0.9475,+/-0.14$ \\
$250 \mathrm{~mW}$ & $0.9564,+/-0.13$ \\
\hline $\begin{array}{l}\text { Note: Average velocity ratios }(+/- \text { standard deviation) for various trap dura- } \\
\text { tions (constant trapping power, } 420 \mathrm{~mW}) \text { and various trapping powers (con- } \\
\text { stant duration } 5 \text { sec). The } 15-\mathrm{sec} \text { trap duration has the greatest average de- } \\
\text { crease in VCL post-trapping. }\end{array}$
\end{tabular}

